\title{
乳用山羊の代謝に関する研究
}

III. 体表面積推定式の決定

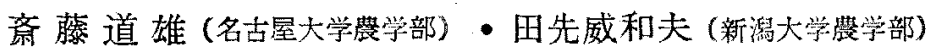

安中昭 雄 (新潟県立加茂農莯高校)

\section{Studies on the metabolism of dairy goat}

III Deciding the formula for calculating the body surface area

Michlo SaITo (Faculty of Agriculture, Nagoya Cniversity), IWAO TAsakI

(Faculty of Agriculture, Niigata University) and AKIO ANXAKA (Kamo

Agricultural High School, Niigata)

\section{I 粕 言}

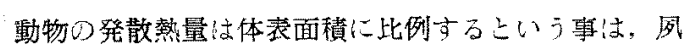
にRUBNER7)により立証されたものであるが，代謝試験

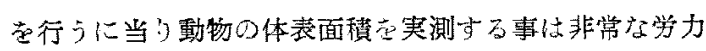

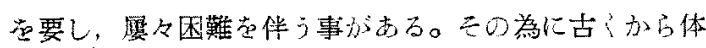

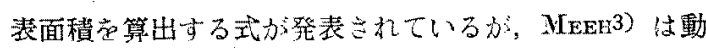
物を単一立体上見做してその体表面積と体重上の数学的

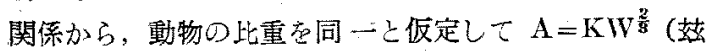
にAは体表面積，Wは体重，Kは常数とする)なる式邑

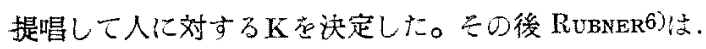

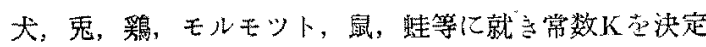
し, 又 Trowbridas et al.9)は牛就いてのK方決定し

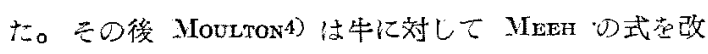
变し, 又 Do Bors et al.1) は体高及ざ体重上り体表面 積学算出する式军人に就いて発表し，更に HoGAN and SkouBY2)は牛及ざ瞅に対して，体長及び体且よりの算出

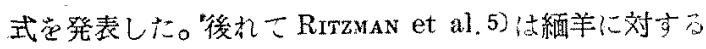
算出式尼決定している。

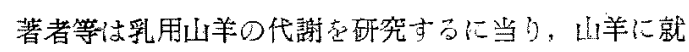
いてこの種の研究が皆無でする事等感したのて，本研 究定行つたのて発替する。

\section{II 実験材料及び測定方法}

供試山羊结新鼬買南蒲原郡森町村, 新潟景種畜場に於

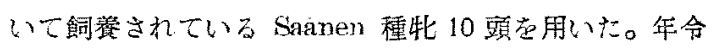
は生後4ケ月より6年に到るまで，体重に16 kg より

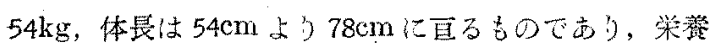
状態も良好なるのから稍々不良すものまで種々存した。

体重は衡器学用いて kg 篻位で測定し, 侉長は HoGAN 等の如，管甲最上端より坐骨末端に到るまでの体表面 に沿つた最短距離虑尺を用いて $\mathrm{cm}$ 位に测定した。 以上は次に述心゙る体表面積測定々略々同時（大体每日正
午附近)に行い，敛水は測定亘前には許可しなかつた。 以上の测定結果は総括して第 1 表に示されている。

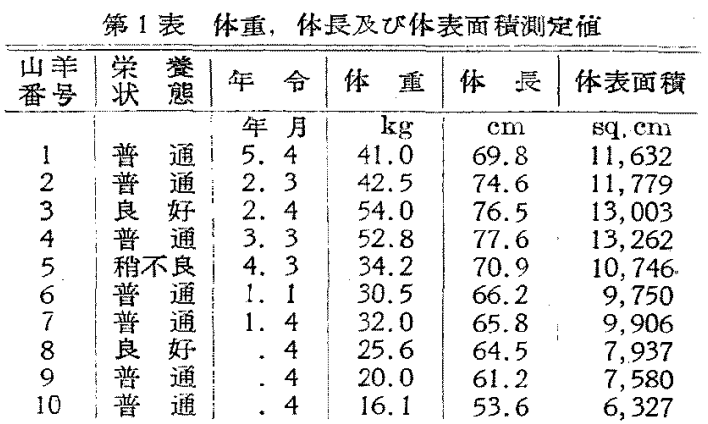

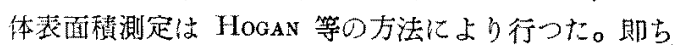
体表の右半部察苜接测定する為, 罳端より尾根に到る背

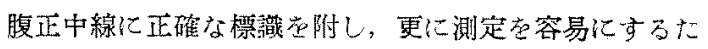

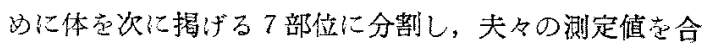

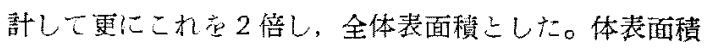
测定に法，马好々ニラパーパーて，0.5，1.0，2.0，2.5 攻じ $3.0 \mathrm{~cm}$ 幅の細带党用意した。一面にアラビアコム

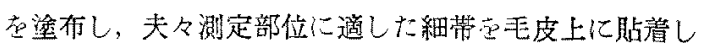
た。无分固著して型在形成古る迄放置し，次いて渐次取 からして各部位の型整作製した。この際供試山羊は先分

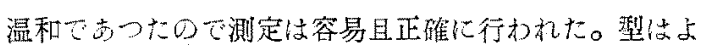

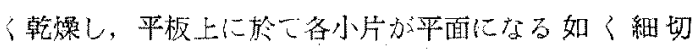
し，之长可及的整一ぬるトレイシングパーパー上に䎐写 訽断して各部位每に科量した。別に一定面積の同質紙 科量して单位面積当りの重量を算出して衫き, 各部位每

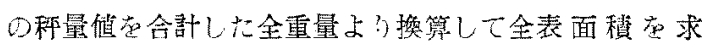
カ，これ第1表にしめした。

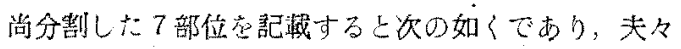
各部值の測定值学表すると第 2 表の如くである。

1) 頭部：第1頸椎と下顎隅在通る線より前位。

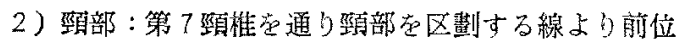
にして頭部より㣪位。 


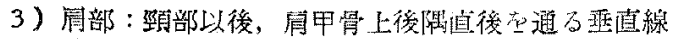
远全

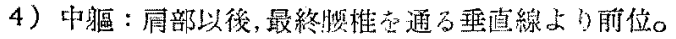

5）後軀：中軀より传位部にして, 後肢を除?。

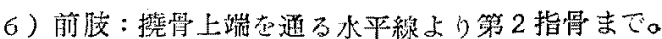

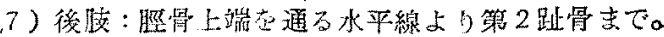

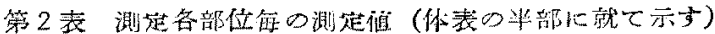

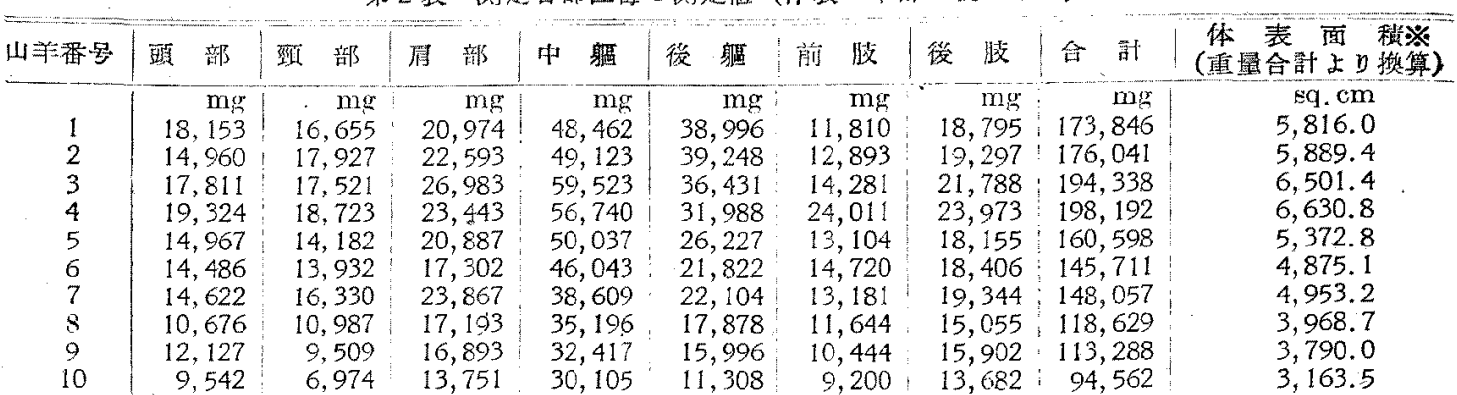

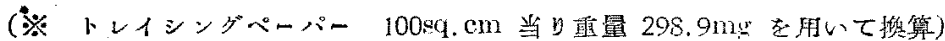

\section{III 体表面積推定式の決定}

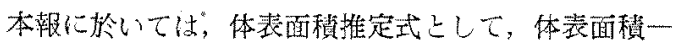
体重の回帰式及び体表面積一体重・体長の回唒式の甪式

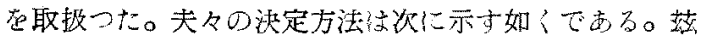

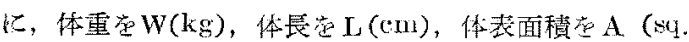
cm) ひ埊した。

A 体表面櫝一体重回帰式口決定。

a) 回㷌式口算出

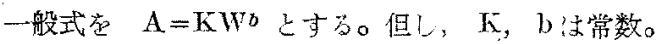
雨辺の効数老七 $b$,

$\log \mathrm{A}=\log \mathrm{K}+\mathrm{b} \log \mathrm{W}$.

$\log \mathrm{A}=\mathrm{Y}, \log \mathrm{W}=\mathrm{X}, \log \mathrm{K}=\mathrm{a}$ 已虬出

$\mathrm{Y}=\mathrm{a}+\mathrm{bx}$

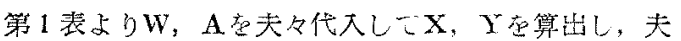
々の合訐在Sで表わすと次表の如々になる。

\begin{tabular}{c|c|c|c|c}
\hline H羊番号 & \multicolumn{1}{|c|}{ W } & \multicolumn{1}{|c|}{$\mathrm{A}$} & $\mathrm{X}$ & \multicolumn{1}{c}{$\mathrm{X}$} \\
\hline 1 & 41.0 & 11632 & 1.61278 & 4.06565 \\
2 & 42.5 & 11779 & 1.62839 & 4.07111 \\
3 & 54.0 & 13003 & 1.73239 & 4.11404 \\
4 & 52.8 & 13262 & 1.72263 & 4.12161 \\
5 & 34.2 & 10746 & 1.53403 & 4.03125 \\
6 & 30.5 & 9750 & 1.48430 & 3.98900 \\
7 & 32.0 & 9906 & 1.50515 & 3.99590
\end{tabular}

$$
\begin{array}{r|r|r|r|r}
8 & 25.6 & 7937 & 1.40824 & 3.89966 \\
9 & 20.0 & 7580 & 1.30130 & 3.87967 \\
01 & 16.1 & 6327 & 1.20683 & 3.80120 \\
\text { 合 } & \text { 就 (S) } & \mathrm{S} \mathrm{X}=15.13577 & \mathrm{~S} \mathrm{Y}=39.96909 \\
\text { 上表より } \\
\quad \bar{y}=\frac{\mathrm{SY}}{\mathrm{n}}=3.99691 \\
\bar{x}=\frac{\mathrm{SX}}{\mathbf{n}}=1.51358
\end{array}
$$

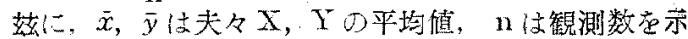

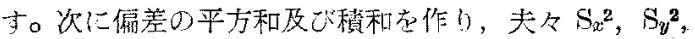
$\mathrm{S}_{x \eta}$ で表わす。

$$
\begin{aligned}
& S_{x^{2}}=S(X-\bar{x})^{2}=0.26633 \\
& S_{y}^{2}=S(X-\bar{y})^{2}=0.11050 \\
& S_{x y}=S(X-\bar{x})(Y-\bar{y})=0.16489
\end{aligned}
$$

\begin{tabular}{|c|c|c|c|c|c|}
\hline 要因 & 自由度 & 平 怔 & 分背 $\left(\begin{array}{ccc}\text { 平 } & \text { 皮 } & \text { 和 } \\
\text { 自 } & \text { 由 } & \text { 㹂 }\end{array}\right)$ & 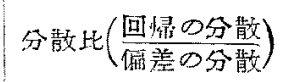 & $\mathbf{F}_{n-2}^{1}$ \\
\hline 回樯 & 1 & $\frac{\left(\mathrm{S}_{x y}\right)^{2}}{\mathrm{~S}_{x^{2}}}=0.10209$ & $\frac{\left(S_{x y}\right)^{2}}{S_{x^{2}}} \div 1=0.10200$ & $\mathrm{~F}=\frac{0.10209}{0.00105}=97.22$ & $\begin{array}{l}>\mathrm{F}_{8}^{1}=25.4 \\
(\mathrm{P}=0.001)\end{array}$ \\
\hline 偏差 & $n-2=8$ & $\mathrm{Sd}^{2} y \cdot x=\mathrm{S}_{y}{ }^{2}-\frac{\left(\mathrm{S}_{x y}\right)^{2}}{\mathrm{~S}_{x^{2}}}=0.00841$ & $\mathrm{~S}^{2} y \cdot x=\frac{\mathrm{Sd}^{2} y \cdot x}{\mathrm{n}-2}=0.00105$ & & \\
\hline
\end{tabular}

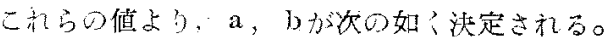

$$
\begin{aligned}
& b=\frac{S_{\text {Jy }}}{S_{x^{2}}}=0.619 \\
& \mathrm{a}=\bar{y}-\mathrm{b} \bar{x}=3.05982
\end{aligned}
$$

俵つ二, $\mathrm{Y}=3.05982+0.619 \mathrm{X}$

即古, $\log \mathrm{A}=3.05982+0.62 \log \mathrm{W}$

又心 $A=1147.7 W^{0.62}$

b) 回㷌の全散分析

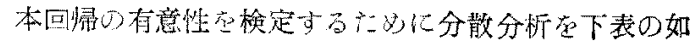

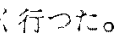

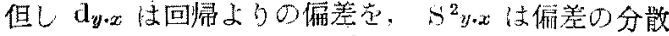

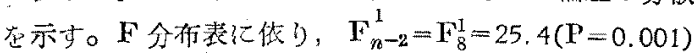
得るのて，分散比 $\mathrm{F}=97.22>25.4-\mathrm{F}_{8}^{2}$ となり，本

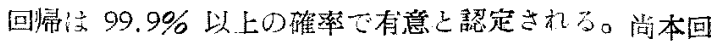

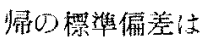

$$
S y \cdot y=\sqrt{\mathrm{S}^{2} y \cdot x}=0.033 \text { б古。 }
$$




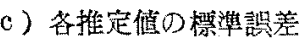

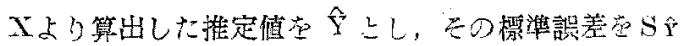

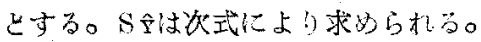

$$
\mathrm{S} \hat{\mathrm{y}}=\mathrm{S} y \cdot x \cdot \sqrt{\frac{1}{\mathrm{n}}+\frac{(\overline{\mathrm{X}}-\bar{x})^{2}}{\mathrm{~S}_{x^{2}}}}
$$

本浿定は自由度 $n-2=8$ でするから， $p=0.05$ 上す

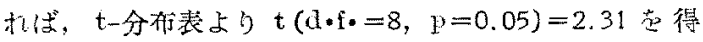

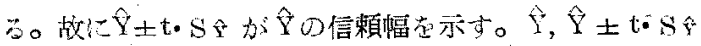

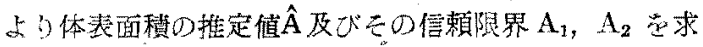

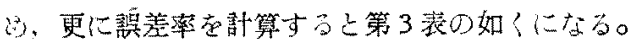

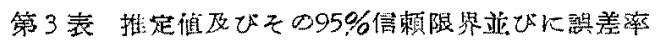

\begin{tabular}{|c|c|c|c|c|c|}
\hline \multirow[b]{2}{*}{$W$} & \multirow[b]{2}{*}{$\hat{A}$} & \multicolumn{2}{|c|}{ 㼘頼限鼠 } & \multicolumn{2}{|l|}{ 䶊 } \\
\hline & & $\mathbf{A}_{1}$ & $\mathbf{A}_{2}$ & $\frac{A_{1}-\hat{A}}{\hat{A}} \times 100$ & $\frac{A_{2}-\hat{A}}{\hat{A}} \times 100$ \\
\hline $\mathrm{kg}$ & $\mathrm{Sq} . \mathrm{cm}$ & $\mathrm{Sq} . \mathrm{cn}$ & $\mathrm{Sq} \cdot \mathrm{cm}$ & $\%$ & 0 \\
\hline 41.0 & 11,411 & 10,74 & 12,124 & -5.88 & 6.25 \\
\hline 42.5 & 11,695 & 10,9 & 2,491 & -6.40 & 6.81 \\
\hline 54.0 & 13,564 & 12,3 & 14,842 & -8.61 & 9.42 \\
\hline 52.8 & 13,376 & 12,25 & 14,597 & -8.36 & 9.13 \\
\hline 34.2 & 10,222 & 9,68 & 10,793 & -5.28 & 5.59 \\
\hline 30.5 & 9,523 & 9,017 & 10,058 & -5.31 & 5.62 \\
\hline 32. & 9,811 & 9,29 & 10,354 & -5.25 & 5.53 \\
\hline 25 & 8,545 & 8,01 & 9,109 & -6.20 & 6.60 \\
\hline 20. & 7,354 & 6,73 & 8,033 & -8.45 & 9.23 \\
\hline 16.1 & 6,410 & 5,71 & 7,190 & $-10,80$ & 12.17 \\
\hline
\end{tabular}

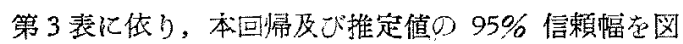
示吉ると第1困の如々になる。

第 1 図 $A=1147.7 W^{0.62}\llcorner こ 095 \%$ 信頼幅

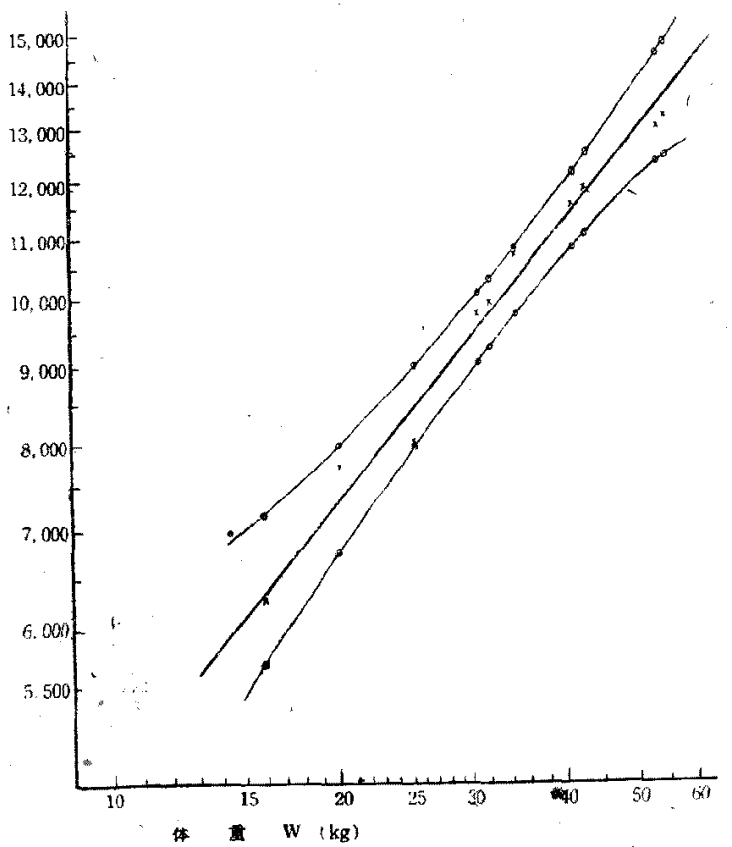

B 体表面櫕一体重・体長回帰式の決定

a) 回帰式の算出

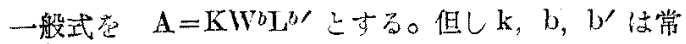

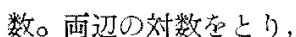

$\log \mathrm{A}=\log \mathrm{K}+\mathrm{b} \log \mathrm{W}+\mathrm{b}^{\prime} \log \mathrm{I}$.

$\log \mathrm{A}=\mathrm{Y}, \quad \log \mathrm{W}=\mathrm{X}_{1}, \quad \log \mathrm{T}_{2}=\mathrm{X}_{2}, \quad \log \mathrm{K}=\mathrm{a} \quad$ と才 れば

$$
\mathrm{Y}=\mathrm{a}+\mathrm{bX} \mathrm{X}_{\mathrm{t}}+\mathrm{b}^{\prime} \mathrm{X}_{2}
$$

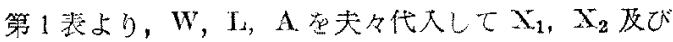

\begin{tabular}{|c|c|c|c|c|c|c|}
\hline 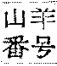 & W & L & A. & $X_{1}$ & $\mathrm{X}_{2}$ & $\mathrm{Y}$ \\
\hline 1 & 41.0 & 69.8 & 11632 & 1.61278 & 1.84386 & 4.06565 \\
\hline 2 & 42.5 & 74.6 & 11779 & 1.62839 & 1.87274 & 4.07111 \\
\hline 3 & 54.0 & 76.5 & 13003 & i. 73239 & 1.88366 & 4.11404 \\
\hline 4 & 528 & 77.6 & 13262 & 1.72263 & 1.88986 & 4. 12161 \\
\hline 5 & 34.2 & 70.9 & $\mid 10746$ & 1.53403 & 1.85065 & 4.03125 \\
\hline 6 & 30.5 & 66.2 & 9750 & 1.48430 & 1.82086 & 3.98900 \\
\hline 7 & 32.0 & 65.8 & 9906 & 1.50515 & 1.81823 & 3.99590 \\
\hline 8 & 25.6 & 64.5 & 7937 & 1.40824 & 1.80956 & 3.89966 \\
\hline 9 & 20.0 & 61.2 & 7580 & 1.30103 & 1.78675 & 3.87967 \\
\hline 10 & 16.1 & 53.6 & 6327 & 1. 20683 & 1.72916 & 3.80120 \\
\hline
\end{tabular}

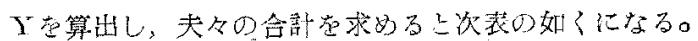
合 訲 (S) $\mid \begin{aligned} & S X_{1} \\ & =15.13577|=18.30533|=39.96909\end{aligned}$ 上表上り

$$
\begin{aligned}
& \bar{y}=\frac{S \mathrm{X}}{\mathrm{n}}=3.99691 \\
& \bar{x}_{1}=\frac{\mathrm{SX}}{\mathrm{n}}=1.51358 \\
& \vec{x}_{2}=\frac{\mathrm{SX_{2 }}}{\mathrm{n}}=1.83053 \\
& \mathrm{~S}_{x_{1}}{ }^{2}=\mathrm{S}\left(\mathrm{X}_{1}-\bar{x}_{1}\right)^{2}=0.26633 \\
& \mathrm{~S}_{x_{2}}{ }^{2}=\mathrm{S}\left(\mathrm{X}_{2}-\bar{x}_{2}\right)^{2}=0.02159 \\
& \mathrm{~S}_{y^{2}}=\mathrm{S}(\mathrm{Y}-\bar{y})^{2}=0.11050 \\
& \mathrm{~S}_{x_{1} x_{2}}=\mathrm{S}\left(\mathrm{X}_{1}-\bar{x}_{1}\right)\left(\mathrm{X}_{2}-\bar{x}_{2}\right)=0.07359 \\
& \mathrm{~S}_{x_{12}}=\mathrm{S}\left(\mathrm{X}_{1}-\bar{x}_{1}\right)(\mathrm{Y}-\bar{y})=0.16489 \\
& \mathrm{~S}_{x_{2 y}}=\mathrm{S}\left(\mathrm{X}_{2}-\bar{x}_{2}\right)(\mathrm{Y}-\bar{y})=0.04546
\end{aligned}
$$

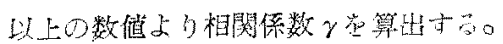

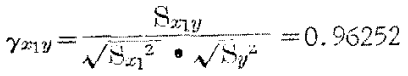

$$
\begin{aligned}
& \gamma_{x y y}=\frac{\mathrm{S}_{x 2 y}}{\sqrt{\mathrm{S}_{x z^{2}}{ }^{2}} \cdot \sqrt{\mathrm{S}_{y^{2}}}}=0.93790 \\
& \gamma_{x_{1} x_{2}}=\frac{\mathrm{S}_{x_{1} x_{2}}}{\sqrt{\mathrm{S}_{u_{1}}{ }^{2}} \cdot \sqrt{\mathrm{S}_{x_{2}{ }^{2}}}}=0.97677
\end{aligned}
$$

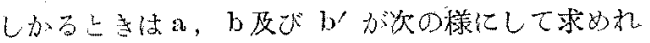
らる

$$
\begin{aligned}
& b=\frac{\gamma_{x_{1} y}-\gamma_{x_{2} y} \cdot \gamma_{x_{1} x_{2}}}{1-\left(\gamma_{x_{1} x_{2}}\right)^{2}} \cdot \frac{\sqrt{\mathrm{S}_{y^{2}}}}{\sqrt{\mathrm{S}_{x_{2}}{ }^{2}}}=0.313 \\
& b^{\prime}=\frac{\gamma_{x_{2} y}-\gamma_{x_{1} y} \cdot \gamma_{x_{1} x_{2}}}{1-\left(\gamma_{w_{1} x_{2}}\right)^{2}} \cdot \frac{\sqrt{\mathrm{S}_{y^{2}}}}{\sqrt{\mathrm{S}_{x_{2}}{ }^{2}}}=1.079 \\
& a=\vec{y}-\left(\mathrm{b} \vec{x}_{1}+b^{\prime} \bar{x}_{2}\right)=1.54849
\end{aligned}
$$

佬つて $\mathrm{Y}=1.54849+0.313 \mathrm{X}_{1}+1.079 \mathrm{X}_{2}$

频 b, $\log \mathrm{A}=1.54849+0.31 \log W+1.08 \log \mathrm{W}$

又は $\mathrm{A}=35.36 \mathrm{~W}^{0.31} \mathrm{~T}^{1.08}$

b）回㷌の分龍分析

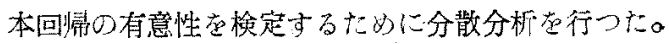




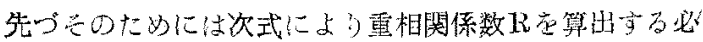
$R=\sqrt{\frac{\left(\gamma_{2} x_{1}\right)^{2}+\left(\gamma_{x_{2} y}\right)^{2}-2 \gamma_{x_{1} y^{*}} \cdot \gamma_{x_{2} y} \cdot \gamma_{x_{1} x_{2}}}{1-\left(\gamma_{x_{2} x_{2}}\right)^{2}}}=0.9526$ 要がある。 次いで分散此さ下瑟の如々求めた。

\begin{tabular}{|c|c|c|c|c|c|}
\hline 要因 & 自由度： & 平 & ，分散( $\left(\begin{array}{lll}\text { 平 } & \text { 方和 } \\
\text { 自 } & \text { 由 } & \text { 度 }\end{array}\right)$ & 分散比 $\left(\begin{array}{l}\text { 回㷌の分散 } \\
\text { 偏差の分散 }\end{array}\right)$ & $\mathrm{F}_{n-3}$ \\
\hline 回㖨 & 2 & $\mathrm{R}^{2} \cdot S y^{2}=0: 1019$ & $\frac{\mathrm{R}^{2} \mathrm{~S}_{y^{2}}}{2}=0.0510$ & $\mathbf{F}=\frac{0.0510}{0.0012}=44.16$ & $\vee F_{7}^{2}=21.7(P=0.001)$ \\
\hline 偏差 & $n-3=7$ & $\left(1-R^{2}\right) s y^{2}=0.0081$ & $S^{2}{ }^{2} y_{x_{1} x_{2}}=\frac{\left(1-R^{2}\right) S y^{2}}{n-3}=$ & & \\
\hline
\end{tabular}

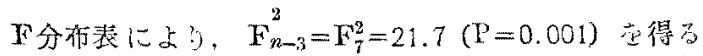

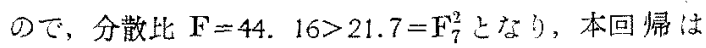

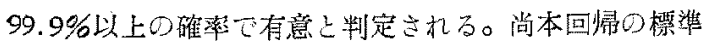
偏差注,

$$
S_{y \cdot x_{2} \lambda_{2}}=\sqrt{S^{2} y_{1} \cdot x_{1} x_{2}}=0.035 \text { である。 }
$$

\section{c) 各推定㑤䅺染梨差}

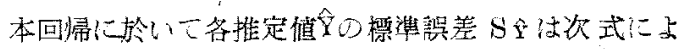

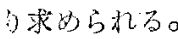

$$
\mathrm{S}_{\hat{\mathrm{Y}}}=\mathrm{S}_{y \cdot c_{1} \times 2} \cdot \sqrt{\frac{1}{11}}+\mathrm{C}_{11}\left(\mathrm{X}_{1}-\bar{x}_{1}\right)+\mathrm{C}_{22}\left(\mathrm{X}_{2}-\bar{x}_{2}\right)+2 \mathrm{C}_{12}\left(\mathrm{X}_{1}-\bar{x}_{1}\right)\left(\mathrm{X}_{2}-\bar{x}_{2}\right)
$$

妓に $\mathrm{O}_{11}, \mathrm{O}_{22}$ 及び $\mathrm{C}_{12}$ 㳉乘数であり，次の如くして 求められる。

$$
\begin{aligned}
& \mathrm{C}_{11}=\frac{H x_{2}^{2}}{S x_{1}^{2} \cdot S x_{2}^{2}-\left(\$ x_{1} x_{2}\right)^{2}}=65.42 \\
& \mathrm{C}_{22}=\frac{\mathrm{s} x_{1}^{2}}{\mathrm{~S} x_{1}^{2} \cdot \mathrm{S} x_{2}^{2}-\left(\mathrm{S} x_{1} x_{2}\right)^{2}}=807.06
\end{aligned}
$$

$$
\mathrm{C}_{12}=\frac{-\mathrm{S} x_{1} x_{2}}{S x_{1}^{2} \cdot S x_{2}^{2}-\left(\mathrm{S} x_{2} x_{2}\right)^{2}}=-223.00
$$

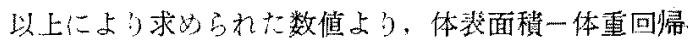

\begin{tabular}{|c|c|c|c|c|c|c|}
\hline \multirow[b]{2}{*}{ W } & \multirow[b]{2}{*}{ L } & \multirow[b]{2}{*}{$\hat{A}$} & \multicolumn{2}{|c|}{ 信 頼 限 界 } & \multicolumn{2}{|c|}{ 樭 $\quad \hat{\mathbf{A}}$} \\
\hline & & & $A_{1}$ & $A_{2}$ & $\frac{A_{1}-\hat{A}}{\hat{A}} \times 100$ & $\frac{A_{2}-\hat{A}}{A} \times 100$ \\
\hline $\mathrm{kg}$ & $\mathrm{en}$ & $\mathrm{sq} \cdot \mathrm{cm}$ & $\mathrm{sq} \cdot \mathrm{cm}^{-}$ & $\mathrm{sq} \cdot \mathrm{cm}$ & $\%$ & $\%$ \\
\hline 41.0 & 69.8 & 11,036 & 10,169 & 11,978 & -7.86 & 8.54 \\
\hline 42.5 & 74.6 & 11,995 & 10,993 & 13,396 & -8.35 & 11.68 \\
\hline 54.0 & 76.5 & 13,280 & 11,972 & 14,731 & -9.85 & 10.93 \\
\hline 52.8 & 77.6 & 13,392 & 12,139 & 14,774 & -9.36 & 10.32 \\
\hline 34.2 & 70.9 & 10,605 & 9,613 & 11,699 & -9.35 & 10.32 \\
\hline 30.5 & 66.2 & 9,523 & 8,948 & 10,089 & -5.83 & 6.18 \\
\hline 32.0 & 65.8 & 9,582 & 8,878 & 10,343 & -7.35 & 7.94 \\
\hline 25.6 & 64.5 & 8,746 & 8,058 & 9,492 & -7.87 & 8.53 \\
\hline 20,0 & 61.2 & 7,649 & 7,125 & 8,212 & -6.85 & 7.43 \\
\hline 16.1 & 53.6 & 6,194 & 5,317 & 7.217 & -14.16 & 16.52 \\
\hline
\end{tabular}
式の場合上同様に测定值W及ごLより算出した推定值 $\hat{A}$

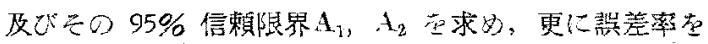
計算して第 4 表に揭げた。

第 4 表 推定值及びその $95 \%$ 信頼限界並びに愦养率

\section{C 両式の比䡚}

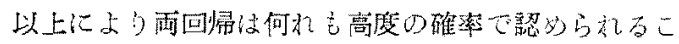
上が分つたので，次比に实際上何れ落用うる方か良いか 定比较㭘封してみた。両式の標淮偏差右見るこ，既に記 した樣に体重のみから換算する式に於いては，

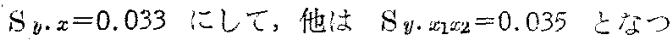

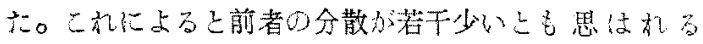
が，この程度の差では前者がより良了適合する乞断定す る事は困難である。又夫々の推定值の誤差率古第 3 蘶友 び第 4 表に就いて此較してみても前者の方が一般に信頼 幅少狭いことが分る。更に䒠際上の取扱いから比䩸する

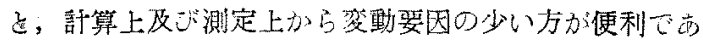

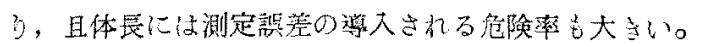

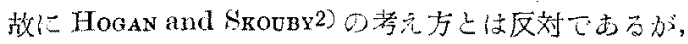

体重の及加ら推定した方がよいと考えられた。依つて著 者等は乳用山羊の体丧而積心推定式として，

$A=1147.7 W^{0.62}$ (但しAは体表面䅡 $(\mathrm{Sq} \cdot \mathrm{cm}) \mathrm{W}^{2}$ 汶体 重 (kgr) 走示寸)上決定しだ。气れによる上本式は

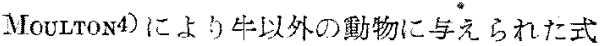

$A=1186 W^{0.625}$ 上非常に良々一致している事が分つ to

\section{IV 本式の応用例一乳用山羊の発生熱量算出}

き红著者等の一人保第1 報8)に於いて，乳用山羊の 熱代謝に就いて報告した。即方餚餓時に於いて体重 $50 \mathrm{~kg}$ 当） 1 日の発生熱量よして 1,018Cal. 驾与无たが，こ

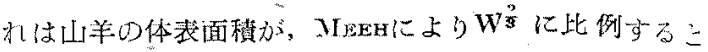
いう理論に基いて計算したものである。本報に依り山羊 
○体表面積は $W^{0.62}$ に比例することが分つたので，これ により再計算すると平均 993Cal. となる。体重 $50 \mathrm{~kg} の$ 山羊の体表面積を $\mathrm{A}=1147.7 W^{0.62}$ に依り算出するこ，

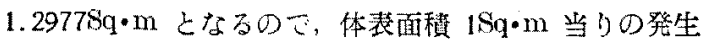

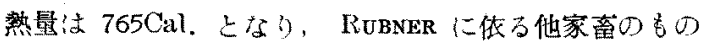
より若干少い事が分つた。

\section{$\mathrm{V}$ 摘 要}

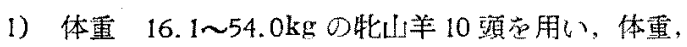

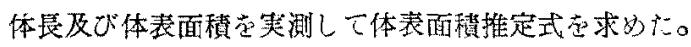

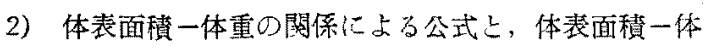
重・体垡の関係にるる公式に就いて比皎孛る上, 理論上 雨者俚略々近似した結果空得たか，実用上から見て前者 ふ便利であると結論しだ。

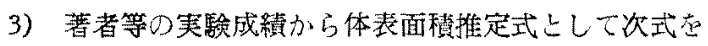
決定した。

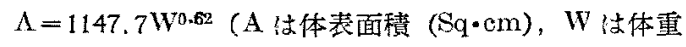
( $\mathrm{kg}$ ) 表走す寸)。

4）第 I 報に報告した山羊の発生熱量再再訫算して，体 重 $50 \mathrm{~kg}$ 当引 $993 \mathrm{Cal}$., $1 \mathrm{Sq} \cdot \mathrm{m}$. 当り $765 \mathrm{Cal}$ ，なる数 値案得广。

本研究実施に当り，山羊口使用起快諾され，更に種々

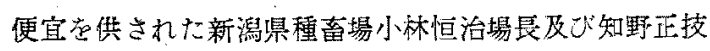

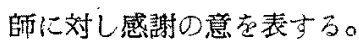

\section{引用文献}

1) Do Bors, D. and Do Bors, E. F. (1915): Arch. Internal Med., 15; 868.

2) Hogan, A. G. and SkoubY, C. I. (1923): J.
Agri.: Res., 25; 419.

3) МЕeH, K. (1879):Z. i. Biol., 15; 425.

4) Moulton, C. R. (1916) : J. Biol. Chem., 24; 299.

5) Ritzman, E. G, et al, (1934): Anm. Rev. Biochem. , 3; 332.

6) Rubner, M. (1833):Z. f. Biol. , 19; 535.

7) - (1894):Z. f. Biol. , 30; 73.

8）田先威和夫(1951)：日本育座学会報，22２２．

9) Trowbridge, P. F., Movlton, C. R. and HaIGH, L. D. (1915) : Mo. Agri. Exp. Sta. Res. Bul.; $18 ; 62$.

(1953.10.30. 受付).

\section{Résumé}

For calculating the surface area of dairy goat, two formulae, that is, the basis of body weight. only and the basis of both body weight and body length, can be considered.

Statistically the difference between two formulae was found to be small; but the formula deduced from the basis of body weight only was found to be practically more superior. The formula found by us is : $A=1147.7 W^{0.62}$ where, $A$ is the surface area in square centimeters, and $\mathrm{W}^{r}$ is the weight of body in kilograms.

The heat production in dairy goat per 1 square meter of body surface was calculated by using the data of the previous report (TASAKI, /5I) and wefound it to be 765 Cal.

\section{外国交献抄録}

The metabolism of nitrate and nitrite in the sheep 2. Hydrogen donators in nitrate reduction by rumen micro-organisms in - vitro.

D. LEwIs (1951) : Biochem. J. 49, 149-153.

第 1 報に於て (抄録, 本誌23巻 4 号143頁参照)，緬羊 の第一胃内に於て硝酸境が严硝酸塩を経てアンモニアに まで選元される事を明らかにしたが，この過程に於ける H-donators が何であるかについては知られて居ない で，第一胃容物上り洗深分離して得た微生物の Suspension を用いてをの in vitro の形究を行つた。乞の結果 $\mathrm{H}_{2}$ ガス住硝酸壏をアンモニアに還元する際に最も有効
な H-donatorであつた（理論值の95〜100\%を示した)。 垔硝酸壏及ぴヒドロオキシルルアミンを亦アンモニアにま で還元されるが，前者仙硝酸塩の還元される際にその初 期の段陼に於て中間物としてあらわれてくる。以上の反 応に於て $\mathrm{H}_{2}$ ガスが硝酸境, 亚硝酸程及びヒドロオキシ

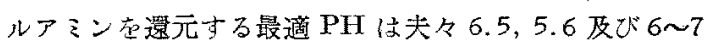
であつt。 Formate, succinate, lactate, citrate, glucose, maltose 及び mannitol 皃硝酸壏還元に際して, H-donator として役立つが，之等は $\mathrm{H}_{2}$ ガスよりずつ 之弱かつた。しかして之等のいられが緬羊第一胃内に 於て，云の微生物による硝酸壏還元の H-donator とし て関与しているか依示さ机なかつゲ。 glycerol，xylose 及び ethanol は殆んど H-donator としての效果が無 々, acetate, propionate 及び $\mathrm{n}$-butyrate は芫全にH一 donator としては不活性でむつた。

(保井忠彦) 